\title{
IN VITRO ACTIVITIES OF POLYMYXINS GROUP COMBINED WITH IMIPENEM OR MEROPENEM AGAINST CARBAPENEM- RESISTANT PSEUDOMONAS AERUGINOSA
}

\author{
Amr Mohamad Basha ${ }^{2 *}$, Gamal M. El-Sherbiny ${ }^{1}$, Mona I. Mabrouk ${ }^{2}$ \\ ${ }^{1}$ Department of Botany and Microbiology, Faculty of Science (Boys), Al-Azhar \\ University, Cairo, Egypt. \\ ${ }^{2}$ Department of Microbiology, National Organization for Drug Control and Research, \\ (Egyptian Drug Authority), Giza, Egypt.
}

*Corresponding author: E-mail: Amohamadbasha@gmail.com

\begin{abstract}
The evaluation of the combined effects between the antibiotics against $P$. aeruginosa is among the efforts to counteract its antimicrobial resistance. This study aimed to evaluate the possible combined effect of colistin or polymyxin-B with carbapenem antibiotic group against clinical isolates of multi-drug resistant $P$. aeruginosa. Strains were isolated from biological samples of hospitalized and nonhospitalized patients with any type of infection related to this pathogen. Only carbapenem-resistant strains were included in the study. After determining the minimum inhibitory concentration (MIC) of antibiotics against the strains by broth microdilution test, the checkerboard method was used for evaluation of any possible effect of both colistin or polymyxin-B with imipenem or meropenem. Fifty-nine strains of reduced susceptibility to carbapenems were recovered. It was noted that $(45.7 \%)$ of strains had an imipenem $\mathrm{MIC}=1024 \mu \mathrm{g} / \mathrm{ml}$ and $(28.8 \%)$ had a meropenem $\mathrm{MIC}=512$ $\mu \mathrm{g} / \mathrm{ml}$. The checkerboard technique demonstrated that the ten representative strains showed reductions in their minimal inhibitory concentration (MIC) for at least one of the antibiotics in the combinations evaluated. These results from the in vitro evaluation suggest that combinations of colistin and polymyxin-B may significantly reduce the MICs of the carbapenem antibiotics tested.
\end{abstract}

Keywords: Carbapenem-resistant $P$. aeruginosa, combination, polymyxin-B, colistin 


\section{Introduction}

P. aeruginosa is the most frequently recovered Pseudomonas strain from clinical specimens and is among the top three causes of opportunistic human infections. Infections due to $P$. aeruginosa are characterized by longer hospitalization periods and high health care costs (Stover et al., 2000). Infections due to this bacterium frequently cause pneumonia and lower respiratory tract infections. It also causes chronic lung infections in patients with cystic fibrosis, urinary tract infections, gastrointestinal, septic shock, bacteremia, septicemia, bone, and joint infections, skin, and soft tissue infections (El Zowalaty et al., 2015). Carbapenems have widely been used as the mainstay for the treatment of severe infections caused by Pseudomonas aeruginosa. This is because they can easily permeate through the porins on the outer membrane of these microorganisms. Unfortunately, a carbapenem-resistant $P$. aeruginosa (CRPA) has now emerged and is disseminating worldwide (Hong et al., 2015). The development of resistant bacterial strains during monotherapy may be a problem and consequently, dual antimicrobial coverage is often employed (Korvick and Yu, 1991). Combination therapy is used to expand the antimicrobial spectrum, minimizing toxicity, preventing the emergence of resistant mutants during therapy, and obtaining synergistic antimicrobial activity. (Song et al., 2003). As few new drugs are available to combat $P$. aeruginosa infections, there has been a return to the use of older drugs such as polymyxins that had previously fallen out of favor due to wide reports of toxic side effects (Livermore, 2002). Despite the reports of nephrotoxicity and neurotoxicity, for patients with $\mathrm{CF}$ suffering recurrent infections of multidrug-resistant bacteria, colistin (a polymyxin drug) has for the past 15 years been routinely administered via inhalation (Falagas and Kasiakou, 2006), demonstrating that the antibiotic resistance problem has been influencing therapeutic choices for many years. Polymyxin B and colistin are the two polymyxins used in clinical practice. Their antimicrobial activity is associated with the detergent effect, which affects the structure and function of the outer membrane of the bacterial cell wall (Michalopoulos and Falagas, 2008). Many studies have demonstrated the efficacy of these agents in the treatment of infections caused by multiresistant bacteria (Landman et al., 2005 and Antoniadou $e$ t al., 2007). This study aims to evaluate the in vitro antimicrobial activity of combinations of polymyxin-B or colistin with the imipenem and meropenem against carbapenem-resistant $P$. aeruginosa.

\section{Materials and methods}

\subsection{Collection of bacterial isolates}

The study was conducted on routine specimens received at the Microbiology section from Kasr El Ainy Hospital (School of Medicine, Cairo University), and El Borg Laboratories over five months between May to September 2017. Bacterial strains were isolated from the following specimens: respiratory specimens (throat swab, nasal swab, Bal and sputum); urinary specimens (urine); skin with abscess and open wound; blood; and ear discharge. These biological samples were collected (either in sterile bottles or in sterile cotton swabs) and shifted to the laboratory for the isolation of $P$. aeruginosa bacterial strains. 


\subsection{Methods of isolation and identification of $P$. aeruginosa}

Blood, urine and sputum samples in addition to all swabs were streaked on MacConkey, Blood and Cetrimide agar plates and incubated at $37^{\circ} \mathrm{C}$ for $24 \mathrm{~h}$. Isolates were recovered and preliminarily identified as Pseudomonas spp. Suspected colonies were stored on Tryptone soya agar slant for further tests. The identity of the isolates was thereafter confirmed after they were transported under sterile conditions to the Department of Microbiology at the National Organization of Drug Control and Research (NODCAR), (Giza, Egypt). Pure colonies of all the isolates were subjected to the standard microbiological and biochemical methods, on the basis of colony morphology on (Pseudomonas agar P), motility, indole, oxidase and catalase reactions, triple sugar iron agar test (TSA), oxidative-fermentative test, citrate utilizing, nitrate reduction, acetamide hydrolysis and growth at $42^{\circ} \mathrm{C}$ (Engelkirk and Duben-Engelkirk, 2008; Mahon et al., 2014).

\subsection{Antibiotics}

Antibiotic powders were obtained from the following pharmaceutical companies in Egypt: polymyxin-B (POX) and colistin (COL) were provided from (Biotika co., Egypt) and (Wakipharma co., Egypt) respectively. Imipenem (IPM) was provided by (Soficopharmco., Egypt), Meropenem trihydrate (MEM) was purchased from (Astrazeneca Egypt, co., inc.); while piperacillin/tazobactam (TZP) from Hikma pharmaceuticals, ceftazidime pentahydrate (CAZ) from Smith Kline Beecham, gentamicin sulfate $(\mathrm{CN})$ from Memphis, levofloxacin (LEV) hemihydrates from SanofiAventis and. All powders were supplied with a stated potency ( $\mu \mathrm{g}$ per g powder). Solvents and diluents were used for each antibiotic as referred by CLSI document M100-S28 (CLSI, 2018).

\subsection{Antimicrobial susceptibility testing of $P$. aeruginosa strains}

Susceptibilities of $P$. aeruginosa strains for antibiotics were quantified as minimum inhibitory concentration (MIC) $(\mu \mathrm{g} / \mathrm{ml})$ by the broth micro-dilution method described by Andrew and Clinical and Laboratory Standards Institute (CLSI) guidelines (Andrews, 2001; CLSI, 2012). The MICs were detected to six selected antibiotics related to five main groups. Stock solutions of the antibiotics were prepared at a concentration of $10.000 \mu \mathrm{g} / \mathrm{ml}$. Given a weighed amount of antibiotic powder, the volume of solvents needed was calculated from the formula:

the volume of solvent $(\mathrm{ml})=$

Weight of powder $(\mathrm{mg}) \times$ potency of powder $(\mathrm{mg} / \mathrm{g})$

Concentration $(\mu \mathrm{g} / \mathrm{ml})$

The method was based on diluting a $10.000 \mu \mathrm{g} / \mathrm{ml}$ stock solution and involved measuring various volumes of antibiotic solutions. A 96-well microtiter plate was removed from its sterile packing and was labeled with the respective antibiotic concentration. Equal volumes $(75 \mu \mathrm{l})$ of each antibiotic dilution and bacterial strain aliquot were dispensed into the respective wells. After overnight incubation at $37^{\circ} \mathrm{C}$, The lowest concentration showing no bacterial growth as evaluated by visual inspection was taken as the MIC value. P. aeruginosa strains were classified according to the 
recently published proposed interim definitions (Magiorakos et al., 2012). A strains was defined as multi drug-resistant $P$. aeruginosa (MDR-PA) if it was resistant to $\geq 1$ agent in $\geq 3$ antimicrobial groups

\subsection{Checkerboard experiments}

Based on the findings of the antimicrobial susceptibility profile, strains that exhibited the highest MIC to carbapenem antibiotics and other related groups indices the most resistant were assessed by the checkerboard technique. It was performed using a two-dimensional checkerboard broth micro-dilution method (Pillai et al., 2005). The combinations tested for each isolate were meropenem plus colistin or polymyxin-B and imipenem plus colistin or polymyxin-B. MICs were previously determined before performing the checkerboard test and repeated on the same day to verify the result. The concentration of colistin or polymyxin-B ranged from $1 / 8 \times$ MIC to $2 \times$ MIC while that of the carbapenem (imipenem or meropenem) ranged from $1 / 32 \times$ MIC to $2 \times$ MIC. Bacterial suspensions were prepared as recommended for MIC determination to yield a final inoculum of $5 \times 10^{5}$ colony-forming units cfu/ml. Aliquots of this suspension were transferred and mixed with an equal volume of antibiotic solutions. The plates were incubated for $18-24 \mathrm{~h}$ at $37^{\circ} \mathrm{C}$ and then interpreted.

Fractional inhibitory concentration index (FIC) calculation: To evaluate the antibacterial effect of each combination, the $\Sigma$ FIC was calculated as follows: FIC index $=$ FIC of drug A + FIC of drug B

The FIC of drug A and drug B was calculated as follows:-

FIC of drug A= MIC of drug A in combination/MIC of drug A alone and FIC of drug B $=$ MIC of drug B in combination/MIC of drug B alone. Synergy was defined as an FIC index $\leq 0.5$, the additive was defined as an FIC index $>0.5$ to $\leq 1$ to, and antagonism was defined as an FIC index $\geq 4$.

\section{Results}

\subsection{Collection of bacterial isolates}

Over the study period, fifty-nine nonconsecutive $P$. aeruginosa isolates were collected as follows; twenty-four strains were from Kasr El Ainy Hospital and thirtyfive strains were collected from El Borg Laboratory. Concerning the specimen site, urine was the major source of the bacterial isolation, comprising 29/59 of the total isolates, the remaining isolates were recovered from wound swabs (13 isolates), sputum samples (7 isolates), nasal swabs (4 isolates), throat swabs (3 isolates), blood samples (1 isolate) and other miscellaneous sources ( 2 isolates). The prevalence of $P$. aeruginosa isolates in different clinical samples is shown in Table (1). 
Table (1): Prevalence of $P$. aeruginosa in different clinical samples

*Bal: bronchoalveolar lavage

\begin{tabular}{|c|c|}
\hline Source & Total no. of isolates (\%) \\
\hline Urine & $29(49.1 \%)$ \\
\hline Wound & $13(22.03 \%)$ \\
\hline Sputum & $7(11.8 \%)$ \\
\hline Throat & $3(5.08 \%)$ \\
\hline \multicolumn{2}{|c|}{ Table (1) continued....... } \\
\hline Blood culture bottles & $1(1.69 \%)$ \\
\hline Nasal & $4(6.77 \%)$ \\
\hline Ear & $1(1.69 \%)$ \\
\hline $\mathrm{Bal}^{*}$ & $1(1.69 \%)$ \\
\hline
\end{tabular}

\subsection{Antimicrobial susceptibility testing of $P$. aeruginosa strains}

Susceptibility profile with MICs data for $59 \quad P$. aeruginosa strains against imipenem, meropenem, ceftazidime, piperacillin/tazobactam, gentamicin, levofloxacin, colistin, and polymyxin-B are summarized in Table (3). It was noted that $27(45.7 \%)$ of strains had an imipenem $\mathrm{MIC}=1024 \mu \mathrm{g} / \mathrm{ml}$ and $17(28.8 \%)$ had a meropenem $\mathrm{MIC}=512 \mu \mathrm{g} / \mathrm{ml}$ ( 8 and 9-folds higher than susceptible MIC breakpoint; $\leq 2 \mu \mathrm{g} / \mathrm{ml}$ respectively). Furthermore, our results revealed that $2(3.4 \%)$ strains were susceptible to meropenem with MIC range between $(1-2 \mu \mathrm{g} / \mathrm{ml})$, and three strains $(5.08 \%)$ had $\mathrm{MIC}=4 \mu \mathrm{g} / \mathrm{ml}$ to imipenem and/or meropenem. In the CLSI guideline, we could categorize these strains as an intermediate resistance. The obtained results revealed that 10/59 $(16.9 \%)$ strains of the carbapenem-resistant $P$. aeruginosa strains had MIC values for ceftazidime below or equal to susceptible MIC breakpoint $(\geq 8$ $\mu \mathrm{g} / \mathrm{ml})$, while $49 / 59(83.05 \%)$ strains had MIC value equal to the resistant MIC breakpoint. It is noteworthy that only two strains are highly resistant to piperacillin/tazobactam with $\mathrm{MIC}=512 \mu \mathrm{g} / \mathrm{ml}$ and almost half the number of strains $27 / 59(45.7 \%)$ have only intermediate resistant MIC. Likewise, only $3 / 59(5.08 \%)$ strains of carbapenem-resistant $P$. aeruginosa had MIC values for gentamicin below resistant MIC breakpoints. On the other hand, regarding the MIC results of levofloxacin antibiotic, it was observed that all strains are resistant and more than one/third of strains 23/59 (38.9\%) have a MIC ranged between 256 to $512 \mu \mathrm{g} / \mathrm{ml}$ (7 to 8-folds higher than susceptible MIC breakpoint; $\leq 2 \mu \mathrm{g} / \mathrm{ml}$ ). Polymyxin-B and colistin showed the highest in vitro activity against the isolates, with a susceptibility rate of $100 \%(n=59)$ for all (MIC range was $1-2 \mu \mathrm{g} / \mathrm{ml}$ ). 
Table (2): MIC ( $\mu \mathrm{g} / \mathrm{ml})$ of $P$. aeruginosa strains to antibiotics

\begin{tabular}{|c|c|c|c|c|c|c|c|c|}
\hline \multirow{3}{*}{ Strains } & \multicolumn{8}{|c|}{ MIC $\mu \mathrm{g} / \mathrm{ml}$ (intermediate resistance breakpoint) } \\
\hline & IPM & MEM & CAZ & TZP & LEV & $\mathbf{C N}$ & POX & COL \\
\hline & $(\geq 4)$ & $(\geq 4)$ & $(\geq 16)$ & $(32 / 4-64 / 4)$ & $(\geq 4)$ & $(\geq 8)$ & $(\geq 4)$ & $(\geq 4)$ \\
\hline Ps-1 & 64 & 64 & $>1024$ & $128 / 4$ & 256 & $>1024$ & 2 & 2 \\
\hline Ps-2 & 1024 & 256 & $>1024$ & $64 / 4$ & 256 & $>1024$ & 2 & 2 \\
\hline Ps-3 & 1024 & 512 & $>1024$ & $128 / 4$ & 128 & $>1024$ & 2 & 2 \\
\hline Ps-4 & 1024 & 256 & 64 & $256 / 4$ & 512 & $>1024$ & 2 & 2 \\
\hline Ps-5 & 1024 & 256 & $>1024$ & $128 / 4$ & 256 & $>1024$ & 2 & 1 \\
\hline Ps-6 & 64 & 256 & 2 & $32 / 4$ & 128 & 1024 & 1 & 1 \\
\hline Ps-7 & 1024 & 256 & 128 & $16 / 4$ & 128 & 1024 & 2 & 2 \\
\hline Ps-8 & 4 & 1 & 8 & $32 / 4$ & 32 & 32 & 1 & 1 \\
\hline Ps-9 & 1024 & 512 & $>1024$ & $128 / 4$ & 128 & $>1024$ & 1 & 2 \\
\hline Ps-10 & 4 & 4 & 4 & $8 / 4$ & 32 & 8 & 2 & 1 \\
\hline Ps-11 & 512 & 128 & $>1024$ & $32 / 4$ & 128 & $>1024$ & 1 & 1 \\
\hline Ps-12 & 1024 & 256 & $>1024$ & $512 / 4$ & 64 & 1024 & 1 & 1 \\
\hline Ps-13 & 512 & 256 & 8 & $32 / 4$ & 64 & 16 & 1 & 1 \\
\hline Ps-14 & 512 & 256 & 32 & $32 / 4$ & 64 & 1024 & 1 & 1 \\
\hline Ps-15 & 1024 & 64 & $>1024$ & $128 / 4$ & 256 & $>1024$ & 2 & 1 \\
\hline Ps-16 & 1024 & 64 & $>1024$ & $128 / 4$ & 256 & $>1024$ & 2 & 1 \\
\hline Ps-17 & 1024 & 64 & $>1024$ & $16 / 4$ & 128 & $>1024$ & 2 & 1 \\
\hline Ps-18 & 512 & 64 & $>1024$ & $64 / 4$ & 256 & $>1024$ & 1 & 1 \\
\hline Ps-19 & 1024 & 512 & $>1024$ & $64 / 4$ & 256 & $>1024$ & 2 & 2 \\
\hline Ps-20 & 1024 & 512 & $>1024$ & $128 / 4$ & 256 & 32 & 2 & 1 \\
\hline Ps-21 & 512 & 64 & 256 & $64 / 4$ & 128 & $>1024$ & 1 & 1 \\
\hline Ps-22 & 1024 & 512 & $>1024$ & $128 / 4$ & 256 & $>1024$ & 2 & 1 \\
\hline Ps-23 & 64 & 256 & $>1024$ & $64 / 4$ & 256 & $>1024$ & 2 & 1 \\
\hline Ps-24 & 64 & 256 & $>1024$ & $64 / 4$ & 256 & $>1024$ & 2 & 1 \\
\hline Ps-25 & 16 & 256 & $>1024$ & $64 / 4$ & 128 & 16 & 1 & 1 \\
\hline Ps-26 & 64 & 32 & 64 & $16 / 4$ & 128 & 16 & 1 & 1 \\
\hline Ps-27 & 32 & 16 & 8 & $16 / 4$ & 256 & 8 & 1 & 1 \\
\hline Ps-28 & 32 & 128 & 8 & $16 / 4$ & 64 & 8 & 2 & 1 \\
\hline Ps-29 & 1024 & 512 & $>1024$ & $128 / 4$ & 256 & $>1024$ & 1 & 1 \\
\hline Ps-30 & 1024 & 512 & 64 & $512 / 4$ & 32 & 32 & 2 & 2 \\
\hline Ps-31 & 1024 & 128 & $>1024$ & $64 / 4$ & 256 & $>1024$ & 2 & 2 \\
\hline Ps-32 & 16 & 32 & 8 & $16 / 4$ & 32 & $>1024$ & 1 & 2 \\
\hline Ps-33 & 8 & 64 & 512 & $128 / 4$ & 16 & $>1024$ & 2 & 2 \\
\hline Ps-34 & 16 & 4 & 4 & $16 / 4$ & 128 & 4 & 2 & 2 \\
\hline Ps-35 & 4 & 2 & 2 & $4 / 4$ & 32 & 4 & 2 & 2 \\
\hline Ps-36 & 16 & 4 & 4 & $32 / 4$ & 64 & 4 & 2 & 2 \\
\hline Ps-37 & 1024 & 512 & $>1024$ & $128 / 4$ & 256 & $>1024$ & 2 & 2 \\
\hline Ps-38 & 1024 & 256 & $>1024$ & $128 / 4$ & 256 & $>1024$ & 2 & 1 \\
\hline Ps-39 & 512 & 256 & $>1024$ & $128 / 4$ & 256 & $>1024$ & 2 & 1 \\
\hline Ps-40 & 64 & 128 & $>1024$ & $64 / 4$ & 256 & $>1024$ & 2 & 2 \\
\hline Ps-41 & 256 & 32 & $>1024$ & $64 / 4$ & 128 & $>1024$ & 1 & 1 \\
\hline
\end{tabular}




\begin{tabular}{|c|c|c|c|c|c|c|c|c|}
\hline Ps-42 & 256 & 128 & 16 & $64 / 4$ & 32 & 8 & 2 & 1 \\
\hline Ps-43 & 64 & 8 & 64 & $32 / 4$ & 64 & $>1024$ & 1 & 1 \\
\hline Ps-44 & 128 & 64 & $>1024$ & $128 / 4$ & 64 & $>1024$ & 2 & 2 \\
\hline Ps-45 & 1024 & 512 & $>1024$ & $256 / 4$ & 512 & $>1024$ & 1 & 2 \\
\hline Ps-46 & 512 & 512 & $>1024$ & $64 / 4$ & 128 & $>1024$ & 2 & 2 \\
\hline Ps-47 & 1024 & 512 & $>1024$ & $64 / 4$ & 64 & $>1024$ & 2 & 2 \\
\hline Ps-48 & 512 & 512 & $>1024$ & $32 / 4$ & 16 & $>1024$ & 2 & 2 \\
\hline Ps-49 & 1024 & 512 & $>1024$ & $128 / 4$ & 256 & $>1024$ & 2 & 2 \\
\hline Ps-50 & 1024 & 512 & $>1024$ & $128 / 4$ & 256 & $>1024$ & 2 & 2 \\
\hline Ps-51 & 512 & 256 & $>1024$ & $32 / 4$ & 128 & $>1024$ & 2 & 2 \\
\hline Ps-52 & 1024 & 256 & $>1024$ & $64 / 4$ & 128 & $>1024$ & 2 & 2 \\
\hline Ps-53 & 1024 & 512 & $>1024$ & $128 / 4$ & 128 & $>1024$ & 2 & 2 \\
\hline Ps-54 & 512 & 64 & $>1024$ & $128 / 4$ & 128 & $>1024$ & 1 & 2 \\
\hline Ps-55 & 16 & 32 & $>1024$ & $64 / 4$ & 128 & 1024 & 2 & 2 \\
\hline Ps-56 & 1024 & 512 & $>1024$ & $64 / 4$ & 256 & $>1024$ & 2 & 2 \\
\hline Ps-57 & 1024 & 256 & $>1024$ & $64 / 4$ & 128 & $>1024$ & 2 & 2 \\
\hline Ps-58 & 1024 & 512 & $>1024$ & $64 / 4$ & 128 & $>1024$ & 2 & 2 \\
\hline Ps-59 & 64 & 32 & 1024 & $128 / 4$ & 128 & $>1024$ & 2 & 2 \\
\hline $\begin{array}{l}\text { Total no. of } \\
\text { highly } \\
\text { resistant }\end{array}$ & 27 & 17 & 41 & 2 & 23 & 46 & 0 & 0 \\
\hline $\begin{array}{l}\text { Total no. of } \\
\text { intermediate } \\
\text { resistant }\end{array}$ & 3 & 3 & 1 & 27 & 0 & 4 & 0 & 0 \\
\hline $\begin{array}{l}\text { Total no. of } \\
\text { sensitive }\end{array}$ & 0 & 0 & 10 & 9 & 0 & 3 & 59 & 59 \\
\hline $\begin{array}{l}\text { Total } \\
\text { MDR }\end{array}$ & \multicolumn{8}{|c|}{59 strains } \\
\hline
\end{tabular}




\subsection{Checkerboard assay}

A checkerboard test was done for ten $P$. aeruginosa stains with the highest MIC values to carbapenem antibiotics as shown in Tables $(3,4,5,6)$ and Figure (1). Although the enhancement factor obtained was apparent over the four combinations, however, the reaction failed to give any synergism against the isolates. As shown in Table 3 and 4 imipenem enhancement factor was noticeable in the presence of colistin and polymyxin$\mathrm{B}$ as the MICs were reduced by 4-fold to 8-fold against 8/10 and 9/10 of strains respectively (the MIC values were decreased from 1024 to $64 \mu \mathrm{g} / \mathrm{mL}$ against more than half of the selected strains). In the combination of polymyxin-B and meropenem, the enhancement factor obtained with these antibiotics was at a lower level (4 times, at most) than imipenem and polymyxin-B, despite this fact, $\sum$ FIC index obtained with those drugs were indicative of a good additive activity (FICI in between 0.62-1). A combination of meropenem with colistin, (Ps-8 and Ps-29) isolates have a 16 times reduction in meropenem MIC respectively, while the reduction rate against the remaining strains was only two-fold.

Table (3): Combination of imipenem and colistin against selected carbapenemresistant $P$. aeruginosa

\begin{tabular}{|c|c|c|c|c|c|c|c|c|c|}
\hline \multirow{2}{*}{ Strains } & \multicolumn{2}{|c|}{ MIC } & \multicolumn{2}{|c|}{ MIC in combinations } & \multicolumn{2}{|c|}{ FIC $^{1}$} & \multirow{2}{*}{$\sum \mathbf{F I C}^{2}$} & \multirow{2}{*}{$\mathbf{E F}^{3}$} & \multirow{2}{*}{ Outcomes } \\
\hline & Imipenem & Colistin & Imipenem & Colistin & Imipenem & Colistin & & & \\
\hline Ps-3 & 1024 & 2 & 64 & 1 & 0.06 & 0.5 & 0.56 & 16 & Additive \\
\hline Ps-9 & 1024 & 2 & 128 & 1 & 0.125 & 0.5 & 0.62 & 8 & Additive \\
\hline Ps-20 & 1024 & 2 & 64 & 1 & 0.06 & 0.5 & 0.56 & 16 & Additive \\
\hline Ps-22 & 1024 & 2 & 128 & 1 & 0.125 & 0.5 & 0.62 & 8 & Additive \\
\hline Ps-29 & 1024 & 2 & 64 & 1 & 0.06 & 0.5 & 0.56 & 16 & Additive \\
\hline Ps-37 & 1024 & 2 & 64 & 1 & 0.06 & 0.5 & 0.56 & 16 & Additive \\
\hline Ps-45 & 1024 & 2 & 512 & 1 & 0.5 & 0.5 & 1 & 2 & Additive \\
\hline Ps-49 & 1024 & 2 & 512 & 1 & 0.5 & 0.5 & 1 & 2 & Additive \\
\hline Ps-50 & 1024 & 2 & 64 & 1 & 0.06 & 0.5 & 0.56 & 16 & Additive \\
\hline Ps-53 & 1024 & 2 & 512 & 1 & 0.5 & 0.5 & 1 & 2 & Additive \\
\hline
\end{tabular}

${ }^{1}$ Fractional inhibitory concentration; ${ }^{2}$ Fractional inhibitory concentration index; ${ }^{3}$

Enhancement factor: Maximum number of times that imipenem antibiotic is reduced in the presence of colistin antibiotic. 
Table (4): Combination of imipenem and polymyxin-B against selected carbapenem-resistant $P$. aeruginosa

\begin{tabular}{|c|c|c|c|c|c|c|c|c|c|}
\hline \multirow{2}{*}{ Strains } & \multicolumn{2}{|c|}{ MIC } & \multicolumn{2}{|c|}{ MIC in combinations } & \multicolumn{2}{|c|}{ FIC $^{1}$} & \multirow{2}{*}{$\sum \mathbf{F I C}^{2}$} & \multirow{2}{*}{$\mathbf{E F}^{3}$} & \multirow{2}{*}{ Outcomes } \\
\hline & Imipenem & Polymyxin B & Imipenem & Polymyxin B & Imipenem & Polymyxin B & & & \\
\hline Ps-3 & 1024 & 1 & 128 & 0.5 & 0.125 & 0.5 & 0.62 & 8 & Additive \\
\hline Ps-9 & 1024 & 1 & 128 & 0.5 & 0.125 & 0.5 & 0.62 & 8 & Additive \\
\hline Ps-20 & 1024 & 1 & 64 & 0.5 & 0.06 & 0.5 & 0.56 & 16 & Additive \\
\hline Ps-22 & 1024 & 1 & 64 & 0.5 & 0.06 & 0.5 & 0.56 & 16 & Additive \\
\hline Ps-29 & 1024 & 1 & 128 & 0.5 & 0.125 & 0.5 & 0.62 & 8 & Additive \\
\hline Ps-37 & 1024 & 1 & 256 & 0.5 & 0.25 & 0.5 & 0.75 & 4 & Additive \\
\hline Ps-45 & 1024 & 1 & 64 & 0.5 & 0.06 & 0.5 & 0.56 & 16 & Additive \\
\hline Ps-49 & 1024 & 1 & 64 & 0.5 & 0.06 & 0.5 & 0.56 & 16 & Additive \\
\hline Ps-50 & 1024 & 1 & 256 & 0.5 & 0.25 & 0.5 & 0.75 & 4 & Additive \\
\hline Ps-53 & 1024 & 1 & 64 & 0.5 & 0.06 & 0.5 & 0.56 & 16 & Additive \\
\hline
\end{tabular}

${ }^{1}$ Fractional inhibitory concentration; ${ }^{2}$ Fractional inhibitory concentration index;

Enhancement factor: Maximum number of times that imipenem antibiotic is reduced in the presence of the polymyxin-B antibiotic.

Table (5): Combination of meropenem and colistin against selected carbapenemresistant $P$. aeruginosa

\begin{tabular}{|c|c|c|c|c|c|c|c|c|c|}
\hline \multirow{2}{*}{ Strains } & \multicolumn{2}{|c|}{ MIC } & \multicolumn{2}{|c|}{ MIC in combinations } & \multicolumn{2}{|c|}{ FIC $^{1}$} & \multirow{2}{*}{$\sum$ FIC $^{2}$} & \multirow{2}{*}{$\mathbf{E F}^{3}$} & \multirow{2}{*}{ Outcomes } \\
\hline & Meropenem & Colistin & Meropenem & Colistin & Meropenem & Colistin & & & \\
\hline Ps-3 & 512 & 2 & 32 & 1 & 0.06 & 0.5 & 0.56 & 16 & Additive \\
\hline Ps-9 & 512 & 2 & 256 & 1 & 0.5 & 0.5 & 1 & 2 & Additive \\
\hline Ps-20 & 512 & 2 & 256 & 0.5 & 0.5 & 0.25 & 0.75 & 2 & Additive \\
\hline Ps-22 & 512 & 2 & 256 & 0.25 & 0.5 & 0.125 & 0.62 & 2 & Additive \\
\hline Ps-29 & 512 & 2 & 32 & 1 & 0.06 & 0.5 & 0.56 & 16 & Additive \\
\hline Ps-37 & 512 & 2 & 256 & 0.25 & 0.5 & 0.125 & 0.62 & 2 & Additive \\
\hline Ps-45 & 512 & 2 & 256 & 1 & 0.5 & 0.5 & 1 & 2 & Additive \\
\hline Ps-49 & 512 & 2 & 256 & 1 & 0.5 & 0.5 & 1 & 2 & Additive \\
\hline Ps-50 & 512 & 2 & 256 & 0.25 & 0.5 & 0.125 & 0.62 & 2 & Additive \\
\hline Ps- 53 & 512 & 2 & 256 & 0.25 & 0.5 & 0.125 & 0.62 & 2 & Additive \\
\hline
\end{tabular}

${ }^{1}$ Fractional inhibitory concentration; ${ }^{2}$ Fractional inhibitory concentration index; ${ }^{3}$

Enhancement factor: Maximum number of times that meropenem antibiotic is reduced in the presence of colistin antibiotic. 
Table (6): Combination of meropenem and polymyxin-B against selected carbapenem-resistant $P$. aeruginosa

\begin{tabular}{|c|c|c|c|c|c|c|c|c|c|}
\hline \multirow{2}{*}{ Strains } & \multicolumn{2}{|c|}{ MIC } & \multicolumn{2}{|c|}{ MIC in combinations } & \multicolumn{2}{|c|}{ FIC $^{1}$} & \multirow{2}{*}{$\sum$ FIC $^{2}$} & \multirow{2}{*}{$\mathbf{E F}^{3}$} & \multirow{2}{*}{ Outcomes } \\
\hline & Meropenem & Polymyxin B & Meropenem & Polymyxin B & meropenem & Polymyxin B & & & \\
\hline Ps-3 & 512 & 1 & 256 & 0.25 & 0.5 & 0.25 & 0.75 & 2 & Additive \\
\hline Ps-9 & 512 & 1 & 256 & 0.5 & 0.5 & 0.5 & 1 & 2 & Additive \\
\hline Ps-20 & 512 & 1 & 128 & 0.5 & 0.25 & 0.5 & 0.75 & 4 & Additive \\
\hline Ps-22 & 512 & 1 & 128 & 0.5 & 0.25 & 0.5 & 0.75 & 4 & Additive \\
\hline Ps-29 & 512 & 1 & 256 & 0.125 & 0.5 & 0.125 & 0.62 & 2 & Additive \\
\hline Ps-37 & 512 & 1 & 128 & 0.5 & 0.25 & 0.5 & 0.75 & 4 & Additive \\
\hline Ps-45 & 512 & 1 & 256 & 0.5 & 0.5 & 0.5 & 1 & 2 & Additive \\
\hline Ps-49 & 512 & 1 & 128 & 0.5 & 0.25 & 0.5 & 0.75 & 4 & Additive \\
\hline Ps-50 & 512 & 1 & 256 & 0.5 & 0.5 & 0.5 & 1 & 2 & Additive \\
\hline Ps-53 & 512 & 1 & 128 & 0.5 & 0.25 & 0.5 & 0.75 & 4 & Additive \\
\hline
\end{tabular}

${ }^{1}$ Fractional inhibitory concentration; ${ }^{2}$ Fractional inhibitory concentration index;

Enhancement factor: Maximum number of times that meropenem antibiotic is reduced in the presence of the polymyxin-B antibiotic.

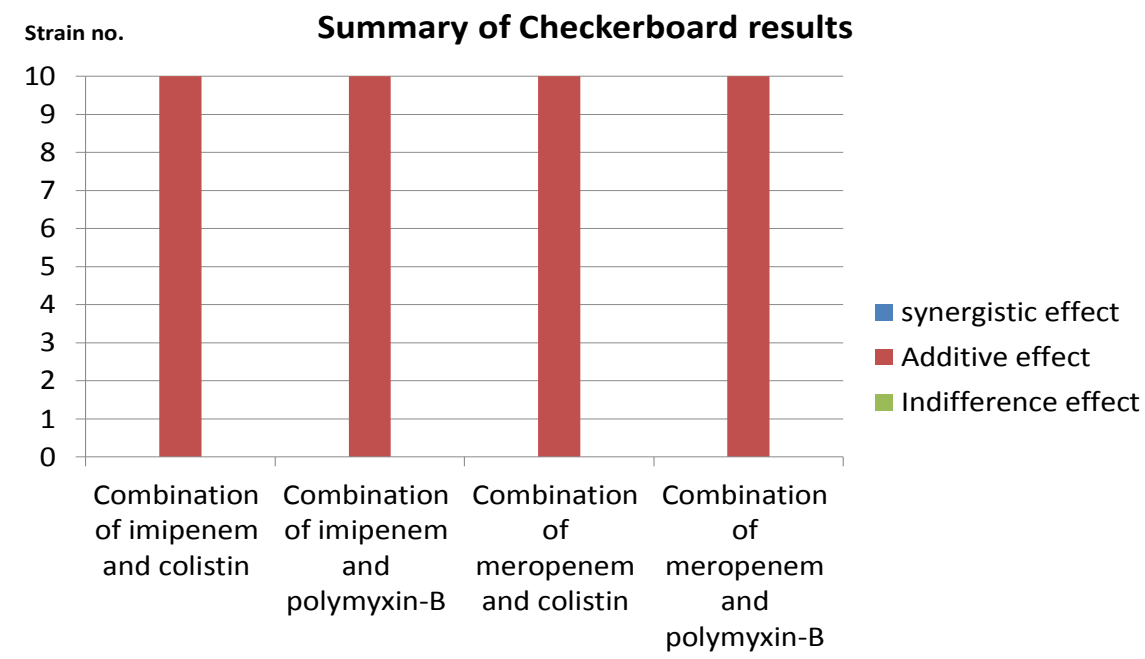

Figure (1): illustrate summary of the checkerboard results of ten selected $P$. aeruginosa strains 


\section{Discussion}

Since 2000, the number of bacterial species carrying ESBL genes has increased, and community-acquired bacterial isolates with the ability to produce ESBLs that hydrolyze almost all $\beta$-lactam agents, except for carbapenems, have been reported worldwide. As a result, the clinical use of carbapenems has increased. This in turn caused an increase in the number of clinical bacterial isolates producing $\beta$ lactamases that have the ability to hydrolyze carbapenems, known as carbapenemases (Tzouvelekis et al., 2012). Thus, the overuse of carbapenems has led to the emergence of carbapenem resistance, which is the ability of bacteria to grow and survive in the presence of clinically relevant carbapenem concentrations (DuranteMangoni et al., 2019). In 2013, we have collected $P$. aeruginosa strains throughout Cairo, Egypt, and the resistance levels to different antibiotics were determined. Data obtained revealed that the most majority of antibiotics (including carbapenems) have little to moderate effects which could give us a warning of the occurrence of outbreaks caused by this pathogen (Mabrouk et al., 2016). Ongoing a more detailed investigation was urgently needed. The present study provides updated compiled information highlighted on the antibiotic resistance patterns and available antimicrobial treatments against carbapenem-resistant $P$. aeruginosa strains in Cairo, Egypt.

In this study, $P$. aeruginosa was isolated and collected from different specimen types (urine, wound, sputum, throat, blood, nasal, ear, and bal) which reflects the ubiquitous nature of the organism as previously reported (Oliver $\boldsymbol{e t}$ al., 2015). Furthermore, the high frequently represented source for the identified $P$. aeruginosa strains was from urine samples (49.1\%). This finding corroborated previous studies that urine was the highest isolation rate (Zarei $\boldsymbol{e t}$ al., 2018; Ullah $\boldsymbol{e t}$ al., 2019).

Determination of MIC values of the carbapenem-resistant $P$. aeruginosa demonstrated that these strains exhibited a high level of resistance to carbapenems. MICs values obtained in this study for carbapenem-resistant $P$. aeruginosa strains against the tested antibiotics were relatively high compared to the MICs values obtained for the antibiotics in other studies from Emirates (Moubareck $\boldsymbol{e t}$ al., 2019), Germany (Kresken et al., 2020), UK (Zamudio et al., 2019), and USA (Kufel et al., 2020). Our data indicated that the situation is more serious than those reported in numerous other countries. This is a public health concern, which requires increased monitoring and implementation of a policy of antibiotics use.

Considering our findings a high degree of cross-resistance was also observed in carbapenem-resistant $P$. aeruginosa to other groups of antibiotics such as, quinolones and aminoglycosides, which further complicate the treatment scenario. These results are consistent with other previous studies that observed the association between carbapenem-resistant in $P$. aeruginosa and high resistance level to levofloxacin and gentamicin (Dogonchi $\boldsymbol{e t}$ al., 2018). The high ratio of co-resistance to quinolone and aminoglycosides among carbapenem-resistant $P$. aeruginosa in this study cast doubt on the efficacy of these classes of antibiotics in treatment.

In the present study polymyxin-B and colistin were deemed to be highly effective antibiotics against all the tested strains. This result suggests that polymyxins 
have increasingly become the last resort drug for treating $P$. aeruginosa infections, especially in seriously ill patients. Our observations agreed with other published reports showed the excellent activity of the polymyxins group against carbapenemresistant $P$. aeruginosa (Azimi et al., 2018; Dogonchi et al., 2018). Unfortunately, polymyxins are highly nephrotoxic agents and the likeliness of renal impairment has been associated with the daily dose of polymyxins (Garonzik et al., 2011 and Dubrovskaya et al., 2015). Hence, the use of polymyxins in combination with other agents may be a successful strategy to minimize polymyxins exposure. Combination therapy is more important for infections with carbapenem-resistant strains, which had a higher percentage of multidrug resistance in the present study. Therefore, we studied the potential of combination therapy against these resistant strains. The combination of polymyxins and imipenem or meropenem showed a noticeable reduction in MIC (in some cases 16 fold reduction in MIC) However, no true synergy was found with the combinations. An unexpected finding in this study was that these regimens only showed additive effects against $P$. aeruginosa isolates in vitro, however, we suppose that any increase in the antibacterial activity using the combination treatment may help clinical success. Furthermore, to date, there have been different criteria upon which to interpret the additive effect of antimicrobial combinations using the checkerboard method. Originally, synergism was defined as an FIC index of 0.5 or less, and additive as an FIC index of $>0.5$ to $\leq 1$ (Pillai et al., 2005). However, another publication recommends another criterion to redefine and additive as an FIC index of 1 and the partially synergistic $(0.5<$ FICI < 1) (Drapeau et al., 2010). Using this criterion, a partial synergism was found in almost all of the combinations tested in our study; nonetheless, imipenem or meropenem plus colistin, and meropenem plus polymyxin-B have only three strains of FIC equal to 1 . Previous studies that evaluated the in vitro antimicrobial synergy of various drug combinations against $P$. aeruginosa focused on carbapenem-resistant (Landman et al., 2005 and Montero et al., 2019). Since the findings of this study were based on a little sample size, the real clinical benefit of using this combination regimen in the treatment of highly carbapenemresistant $P$. aeruginosa infections still needs to be established.

\section{Conclusion}

The combination of polymyxins group + carbapenem group demonstrated a good efficiency in vitro against carbapenem-resistant $P$. aeruginosa isolates that showed a multi-resistance to another antimicrobial especially fluoroquinolones, aminoglycosides, and cephalosporins. In addition, such combination therapy avoids the risk for acute kidney injury induced by colistin or polymyxin-B which is especially important in patients with renal insufficiency.

\section{REFERENCES}

Andrews, JM. (2001). Determination of minimum inhibitory concentrations. $J$ Antimicrob Chemother 48: 5-16.

Antoniadou, A., Kontopidou, F., Poulakou, G., Koratzanis, E., Galani, I., Papadomichelakis, E. et al. (2007). Colistin-resistant isolates of Klebsiella pneumonia emerging in intensive care unit patients: first report of a multiclonal cluster. J Antimicrob Chemother 59:786-790. 
Azimi, A., Peymani, A., and Pour, P.K. (2018). Phenotypic and molecular detection of Metallo- $\beta$-lactamase-producing Pseudomonas aeruginosa isolates from patients with burns in Tehran.Iran Rev Soc Bras Med Trop 51(5): 610-615.

CLSI (2012). Methods for Dilution Antimicrobial Susceptibility Tests for bacteria That Grow Aerobically; Approved Standard-9th ed. CLSI document M07-A9 Clinical and Laboratory Standards Institute, Pennsylvania, USA.

CLSI (2018). Performance Standards for Antimicrobial Susceptibility Testing; 28th ed Informational Supplement. CLSI document M100-S28. Clinical and Laboratory Standards Institute, Pennsylvania, USA.

Dogonchi, A.A., Ghaemi, E.A., Ardebili, A., Yazdansetad, S., and Pournajaf, A. (2018). Metallo- $\beta$-lactamase-mediated resistance among clinical carbapenemresistant Pseudomonas aeruginosa isolates in northern Iran: A potential threat to clinical therapeutics. Tzu Chi Med J 30(2): 90-96.

Drapeau, C.M., Grilli, E., and Petrosillo, N. (2010). Rifampicin combined regimens for gram-negative infections: data from the literature. Int $J$ Antimicrob Agents 35(1): 39-44.

Dubrovskaya, Y., Prasad, N., Lee, Y., Esaian, D., Figueroa, D.A., Tam, V.H. (2015). Risk factors for nephrotoxicity onset associated with polymyxin B therapy. J Antimicrob Chemother 70:1903-1907.

Durante-Mangoni, E., Andini, R., and Zampino, R. (2019). Management of carbapenem-resistant Enterobacteriaceae infections. Clin Microbiol Infect 25(8): 943-950.

El Zowalaty, M.E., Al Thani, A.A., Webster, T.J., El Zowalaty, A.E., Schweizer, H.P., Nasrallah, G.K., et al. (2015). Pseudomonas aeruginosa: the arsenal of resistance mechanisms, decades of changing resistance profiles, and future antimicrobial therapies. Futur Microbio 10(10):1683-1706.

Engelkirk, P., and Duben-Engelkirk, J. (2008). Laboratory diagnosis of infectious diseases. Philadelphia: Lippincott Williams and Wilkins.

Falgas, M.E., and Kasiakou, S.K. (2006). Toxicity of polymyxins: a systematic review of the evidence from cold and recent studies. Crit Care 10(1): R27.

Garonzik, S.M., Li, J., Thamlikitkul, V., Paterson, D.L., Shoham, S., Jacob, J. et al. (2011). Population pharmacokinetics of colistin methanesulfonate and formed colistin in critically ill patients from a multicenter study provide dosing suggestions for various categories of patients. Antimicrob Agents Chemother 55:3284-3294.

Hong, D.J., Bae, K., Jang, I., Jeong, S., Kang, H., and Lee, K. (2015). Epidemiology and Characteristics of Metallo- $\beta$ - Lactamase-Producing Pseudomonas aeruginosa. Infect Chemother 7(2): 81-97. 
Korvick, J.A., Yu, V.L. (1991). Antimicrobial agent therapy for Pseudomonas aeruginosa. Antimicrob Agents Chemother 35:2167-2172.

Kresken, M., Körber-Irrgang, B., Korte-Berwanger, M., Pfennigwerth, N., Gatermann, S.G., and Seifert, H. (2020). Dissemination of carbapenemresistant Pseudomonas aeruginosa isolates and their susceptibilities to ceftolozane-tazobactam in Germany. Int J Antimicrob Agents 55(6): 1-10.

Kufel, W.D., Steele, J.M., Riddell, S.W., Jones, Z., Shakeraneh, P., and Endy, T.P. (2020). Cefiderocol for treatment of an empyema due to extensively drug-resistant Pseudomonas aeruginosa: Clinical observations and susceptibility testing considerations. IDCases 3(21): 1-6.

Landman, D., Bratu, S., Alam, M., and Quale, J. (2005). Citywide emergence of Pseudomonas aeruginosa strains with reduced susceptibility to polymyxin B. J Antimicrob Chemother 55(6): 954-975.

Livermore, D.M. (2002). Multiple mechanisms of antimicrobial resistance in Pseudomonas aeruginosa: our worst nightmare?. Clin Infect Dis 34: 634-640.

Mabrouk, M.I., El-Hendawy, H.H., Basha, A.M., and Saleh, N.M. (2016). Prevalence, antibiotic, and oil resistance pattern of some bacterial isolates from burns. J App Pharm Sci 6(06): 123-130.

Magiorakos, A.P., Srinivasan, A., Carey, R.B, Carmeli, Y., Falagas, M.E., Giske, C.G., et al. (2012). Multidrug-resistant, extensively drug-resistant and pandrug-resistant bacteria: an international expert proposal for interim standard definitions for acquired resistance. Clin Microbiol Infect 18: 268-281.

Mahon, C.R., Lehman, D.C., and Manuselis, G. (2014). Text book of diagnostic microbiology. 5 th edn. Missouri, U.S.A: W.B. Saunders.

Michalopoulos, A., Falagas, M.E. (2008). Colistin and polymyxin B in critical care. Crit Care Clin 24:377-391.

Montero, M.M., Domene Ochoa, S., Lopez-Causape, C., VanScoy, B., Luque, S., Sorlí, L. et al. (2019). Colistin plus meropenem combination is synergistic in vitro against extensively drug-resistant (XDR) Pseudomonas aeruginosa, including high-risk clones. J Global Antimicrob Resist 18: 37-44.

Moubareck, C.A., Halata, D.H., Akkawia, C., Nabi, A., AlSharhan, M.A. AlDeesie, Z.O., et al. (2019). Role of outer membrane permeability, efflux mechanism, and carbapenemases in carbapenem-nonsusceptible Pseudomonas aeruginosa from Dubai hospitals: Results of the first cross-sectional survey. Int J Infect Dis 84: 143-150.

Oliver, A., Mulet, X., López-Causapé, C., and Juan, C. (2015). The increasing threat of Pseudomonas aeruginosa high-risk clones. Drug Resist Updat 21-22: 41-59. 
Pillai, S.K., Moellering, R.C., and Eliopoulos, G.M. (2005). Antimicrobial Combinations. In: Lorian V (ed) Antibiotics in Laboratory Medicine, $5^{\text {th ed. }}$ The Lippincott Williams \& Wilkins Co., Philadelphia, 365-440.

Song, W., Woo, H.J., Kim, J.S., Lee, K.M. (2003). In vitro activity of $\beta$-lactams in combination with other antimicrobial agents against resistant strains of Pseudomonas aeruginosa. Inter J of Antimicrobial Agents 21(1): 8-12.

Stover, C., Pham, X., Erwin, A., et al. (2000). Complete genome sequence of Pseudomonas aeruginosa PAO1, an opportunistic pathogen. Nature 406(6799): 959-964.

Tzouvelekis, L.S., Markogiannakis, A., Psichogiou, M., Tassios, P.T., and Daikos, G.L. (2012). Carbapenemases in Klebsiella pneumonia and other Enterobacteriaceae: an evolving crisis of global dimensions. Clin Microbiol Rev 25(4): 682-707.

Ullah, N., Güler, E., Güvenir, M., Arıkan, A., and Süer, K. (2019). Isolation, Identification, and Antibiotic Susceptibility Patterns of Pseudomonas aeruginosa Strains from Various Clinical Samples in a University Hospital in Northern Cyprus. Cyprus J Med Sci 4(3): 225-228.

Zamudio, R., Hijazi, K., Joshi, C., Aitken, E., Oggioni, M.R., and Gould, I.M. (2019). Phylogenetic analysis of resistance to ceftazidime/avibactam, ceftolozane/tazobactam, and carbapenems in piperacillin/tazobactam-resistant Pseudomonas aeruginosa from cystic fibrosis patients. Int J Antimicrob Agents 53(6): 774-780.

Zarei, O., Shokoohizadeh, L., Hossainpour, H. and Alikhani, M.U. (2018). Molecular analysis of Pseudomonas aeruginosa isolated from clinical, environmental, and cockroach sources by ERIC-PCR. BMC Res Notes 11: 668 . 


\section{دراسات معملية لبحث تفاعل واتحاد مجموعة البوليميكسينات مع الإميبينيم والميروبينيم لوقف إئف

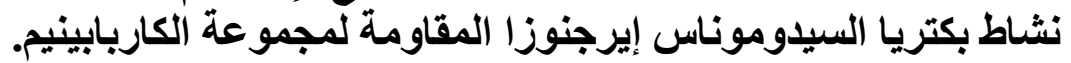

$$
\begin{aligned}
& \text { عمرو محمد باثنا محمد ץ" ، جمال محمد السعيد الثربينى' ، منى إبر اهيم مبروك إبراهيمَ } \\
& \text { 'قسم النبات و الميكروبيولوجى ـ كلية العلوم (بنين)، جامعة الأزهر - القاهرة ـمصر. }
\end{aligned}
$$

ץ قيم الميكروبيولوجى ـ الهيئة القومية للرقابة و البحوث الدوائية (هيئة الدواء المصرية)، الجيزة، مصر.

Amohamadbasha@gmail.com البريد الاكترونى للباحث الرئيسي: *

تعتبر السيدوموناس إيرجنوزا أحد أكثر أنواع البكتريا شيوعا حيث تنتواجد في معظم البيئات الطبيعية

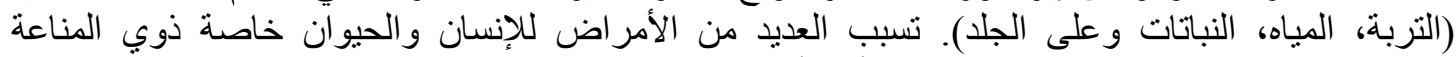

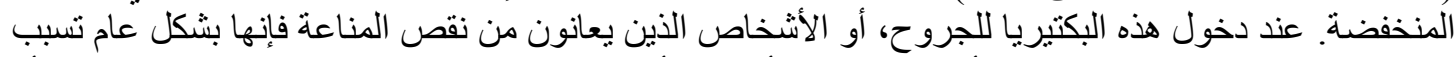

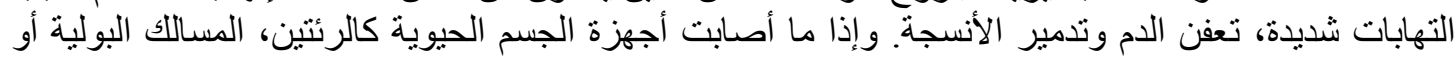

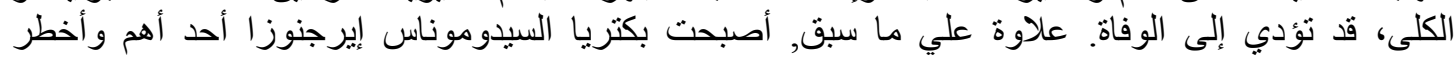

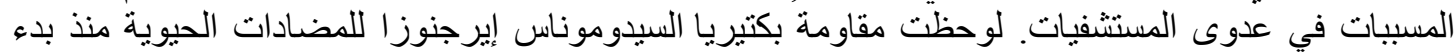

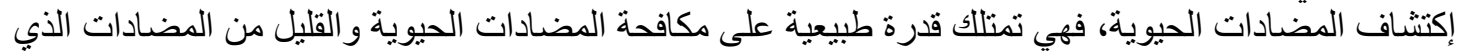

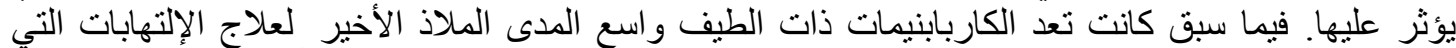

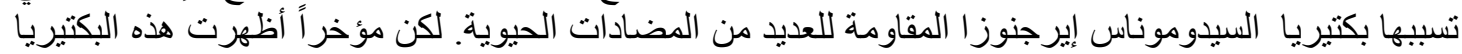

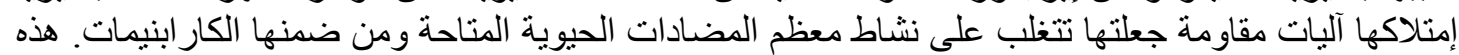

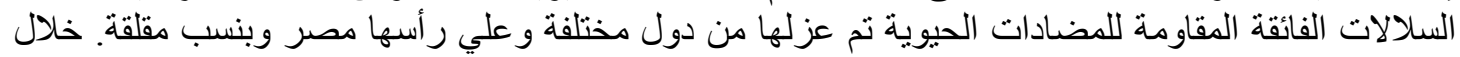

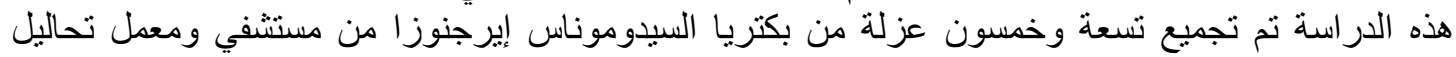

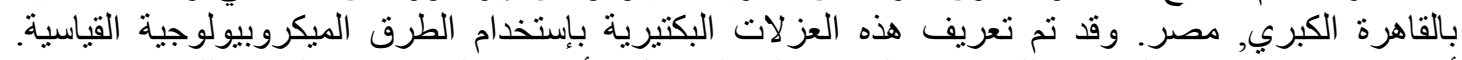

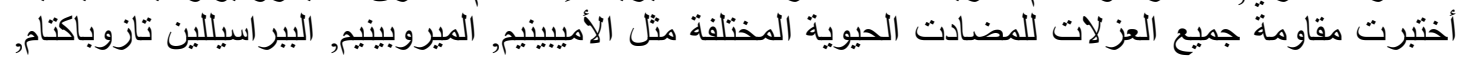

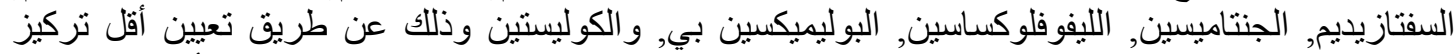

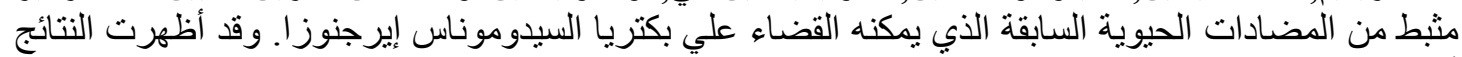

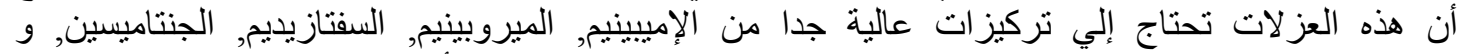

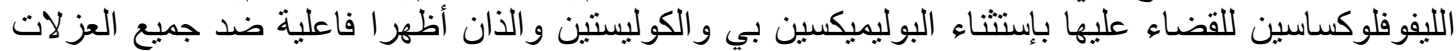

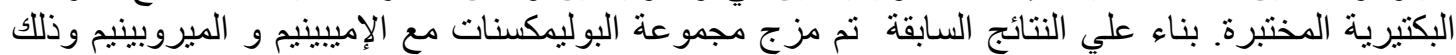

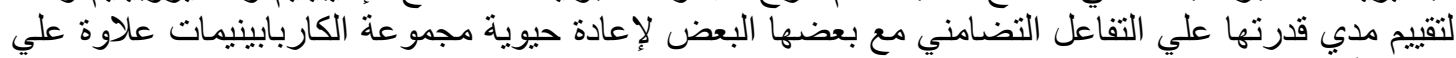

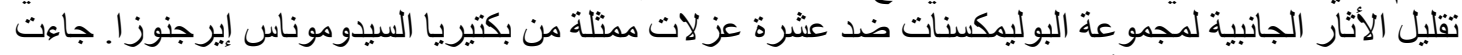

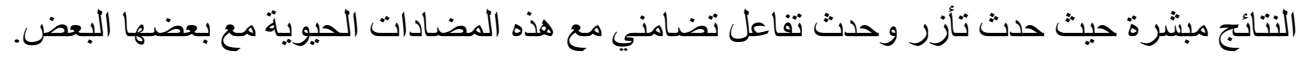

الكلمات المفتاحية:- السيدوموناس إيرجنوز المقاومة لمجموعة الكاربابينيه.، إتحاد، بوليميكسين بي، كولستين. 